\title{
Studies on cleaning validation for a cream and ointment manufacturing line
}

\author{
Aliaa A Badawi ${ }^{1}$, Khaled Hegazy ${ }^{2}$, Dina Louis ${ }^{1 *}$ \\ 1Department of Pharmaceutics and Industrial Pharmacy, Faculty of Pharmacy, Cairo University, 2Central Administration of \\ Pharmaceutical Affairs, Cairo, Egypt \\ *For correspondence: Email: dinalouis@hotmail.com, Dina.nassif@pharma.cu.edu.eg; Tel: 0202-0122 8866769
}

\begin{abstract}
Purpose: To validate a new and simple method for cleaning a manufacturing line for creams and ointments.

Methods: The worst case product of the line chosen was a cream containing three practically insoluble ingredients: betamethasone, tolnaftate and cliquinol. The cleaning method utilized hot water and a commercial detergent, followed by rinsing. Validation methods included the visual inspection of the machine surface, swab sampling, microbial bioburden determination and testing the final rinse for conductivity, $\mathrm{pH}$ and total organic carbon (TOC) limits. Acceptance limit calculations depended on the figure tip unit (FTU).

Results: No visual residue or chemical residue was detected above $674.37 \mathrm{ppm}$, which is the maximum allowable carry-over level of the drug. Similarly, microbial bioburden was < 25 CFU/swab - the acceptable limit.

Conclusion: The method adopted to get rid of insoluble drug residue and microorganism from the cream and ointment production facility was successful. The method is simple and reproducible as indicated by the results of the three cleaning cycles.
\end{abstract}

Keywords: Validation, Worst case product, Swab sampling, Finger-tip unit, Acceptance limits, Cream and ointment manufacturing line

Tropical Journal of Pharmaceutical Research is indexed by Science Citation Index (SciSearch), Scopus, International Pharmaceutical Abstract, Chemical Abstracts, Embase, Index Copernicus, EBSCO, African Index Medicus, JournalSeek, Journal Citation Reports/Science Edition, Directory of Open Access Journals (DOAJ), African Journal Online, Bioline International, Open-J-Gate and Pharmacy Abstracts

\section{INTRODUCTION}

Pharmaceutical products can be contaminated by a variety of substances, such as microbes and previous products (both active pharmaceutical ingredients and excipient residues). Other contaminants include residues of cleaning agents, airborne materials, and ancillary materials such as disinfectants. Contamination can also occur due to decomposition of product residue and breakdown products of the detergents, acids and alkalis that may be used as part of the cleaning process [1].
Cleaning validation is a documented proof that one can consistently and effectively clean a system or equipment items [2]. Cleaning involves removing an unwanted substance (the contaminant) from a surface (the equipment to be cleaned) [3-5]. The cleaning mechanisms depend on properties of the contaminant to be removed. Cleaning of manufacturing machines can be carried out using methods as "Clean in place (CIP)" [6], "Clean out of place (COP)" [7] and "Manual cleaning" $[7,8]$.

There is a time limitation, such as microbiological contamination or carryover of degradation 
products which might develop with time, or simply the ease of cleaning residues of product before they dry out on the equipment [9]. There are four time limitations: Clean holding time $[10,11]$, dirty holding time $[9,10]$, time between the cleaning and drying process [9] and a time limitation related to the frequency of cleaning between batches [9].

Cleaning can be achieved through the use of water, solvents, commodity chemicals and formulated cleaning agents $[3,9,12]$.

Elements of cleaning validation[1,8], include worst case determination [1,13,14], establishment of acceptance criteria $[15,16]$, sampling procedure $[1,17,18]$, analytical method and its validation $[13,19]$, validation protocol $[1,6,17,20]$, and cleaning validation report $[1,21]$.

Topical semi-solid formulations such as creams and ointments contain greasy ingredients such as waxes and oils. These ingredients may inhibit wetting by cleaning agents, thereby limiting the ability to clean the residual product away [22]. The active pharmaceutical ingredients and excipients commonly used in topical formulations may produce significant adverse effects. Therefore, one must determine the carryover of residues from one product to another in a scientifically justified manner to limit the possible interactions between products and their ingredients [22].

Hence, the objective of the work was to validate the suggested cleaning procedure and ensure that residues of previous product are removed in accordance with the maximum allowable carryover limit calculated

The minimum and maximum daily dose of topical formulations can be calculated based on the criteria of finger-tip unit (FTU). This criterion describes the dosage of topical formulations. [23]. Accordingly, the maximum allowable carryover limit can be calculated from Eq 1 [24].

$\mathrm{MACO}=(\mathrm{TDD} \times \mathrm{MBS} \times \mathrm{SF}) / \mathrm{LDD}$

Where, MACO is the maximum allowable carryover, TDD the minimum daily dose of the previous product, and MBS the minimum batch size of next product. It is obtained from the product matrix; LDD is the largest daily dose of the next product; SF is the safety factor $=1 / 100$ for topical products [25].
Calculation of limit in the analyzed sample is as in Eq 2.

$$
\text { MACOs }=(\text { MACO cal } \times \text { SA } \times \text { RF }) /(\text { TSA } \times E V) . .
$$

where, MACOs is the maximum allowable carryover in the sample, MACO cal is the calculated MACO, SA is the area swabbed $=25$ $\mathrm{cm}^{2}$; TSA is the total equipment surface area that comes in contact with the product; RF is the recovery factor; $\mathrm{EV}$ is the extraction solvent volume ( the volume used to extract residue from swab head $=5 \mathrm{ml})[1,17]$.

\section{EXPERIMENTAL}

\section{The cream and ointment facility}

The cleaning process and its validation were performed for a cream and ointment production line involved in the production of twenty one products. The validation process involved three consecutive batches of the worst-case product.

The facility consisted of three main parts: the cream and ointment preparation tank (Olsa S.P.V, Milano, Italy) (Figure 1), where mixing and homogenization of the bulk took place. The transfer bin (Figure 2), received the bulk prepared cream and ointment from the preparation tank which would be transferred to the third part: cream and ointment filling machine (Tonazzi, Marchesini group, Bologna, Italy) (Figure 3). A vacuum and pressure pump (Figure 4) transferred the bulk cream or ointment to the filling machine hopper (Figure 5).

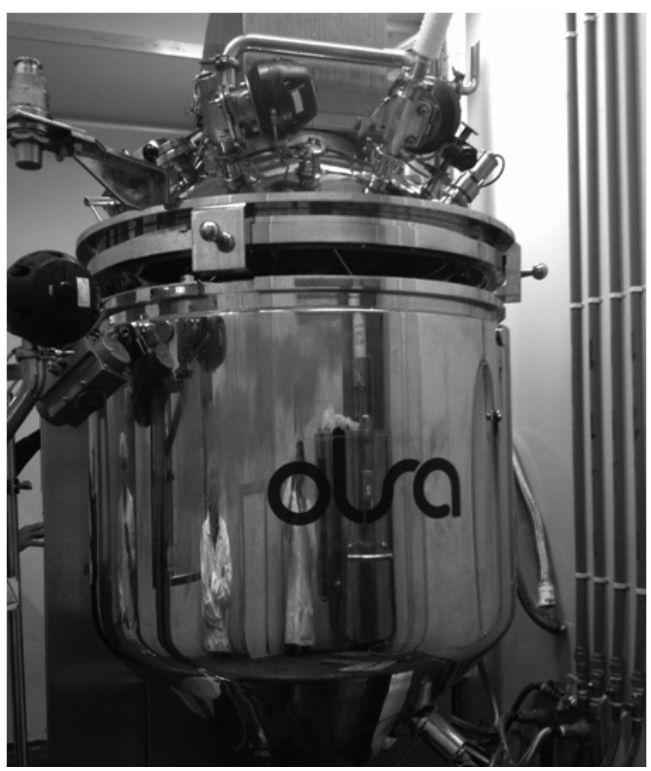

Figure 1: Cream and ointment preparation tank (OLSA 500) 


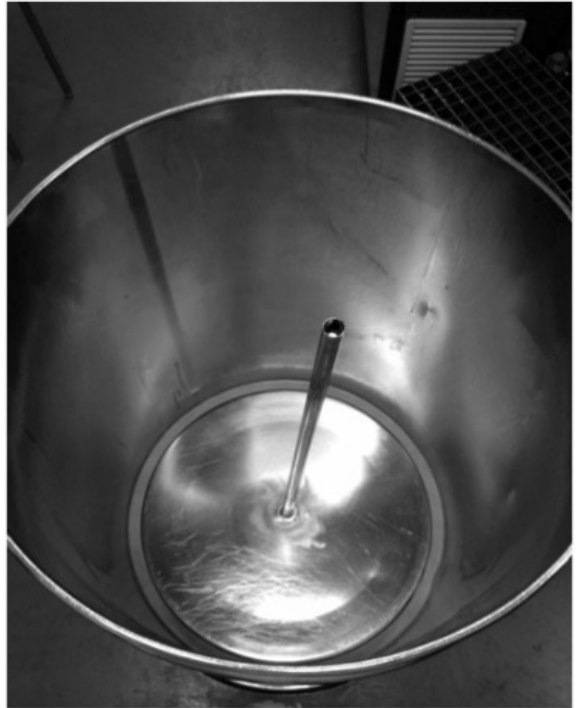

Figure 2: Transfer bin

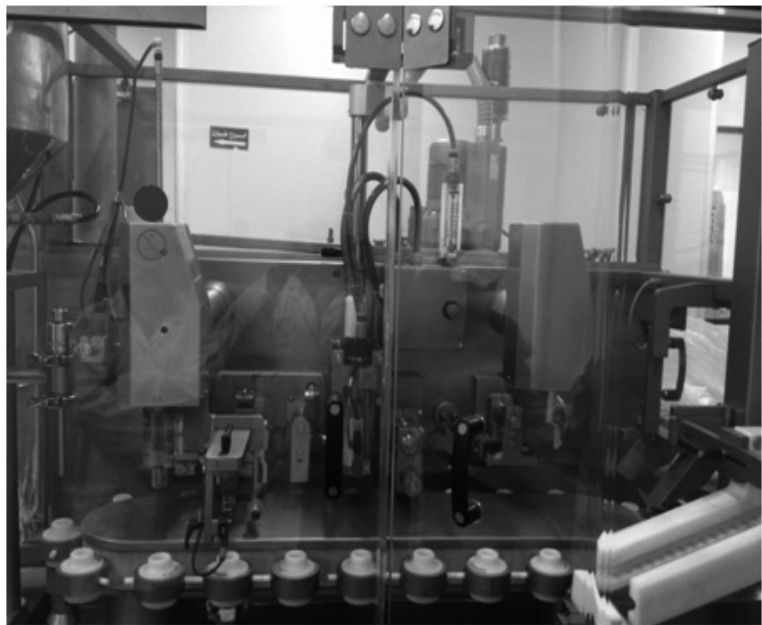

Figure 3: Cream and ointment filling machine Tonazzi

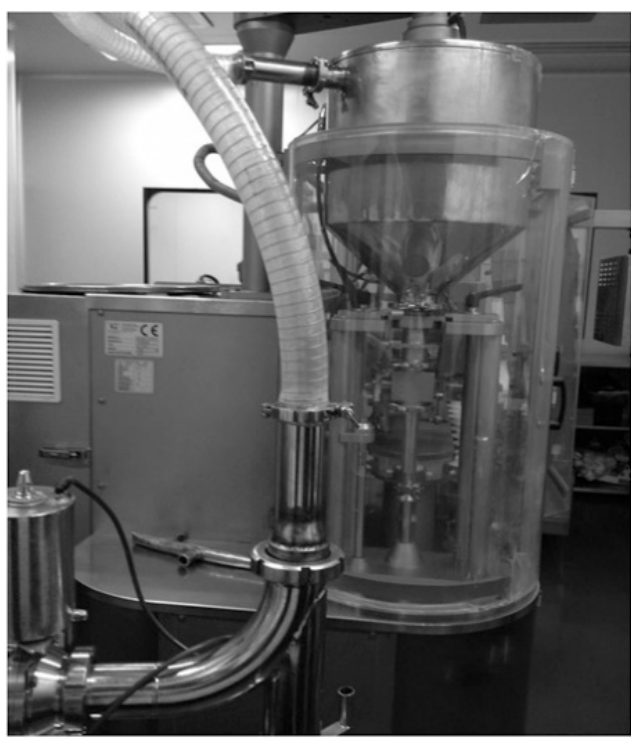

Figure 4: Connection between transfer bin and hopper

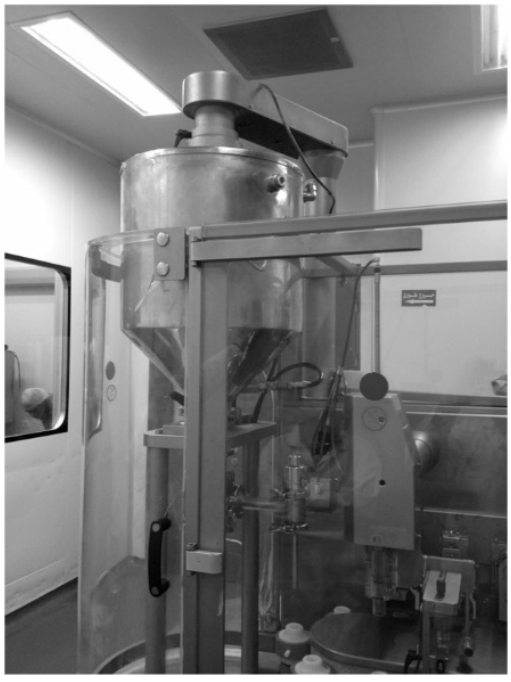

Figure 5: Feeding hopper and filling nozzle

This facility was used to prepare 21 products. The worst case product chosen for the validation of the cleaning procedure was chosen based on the solubility of the active ingredients and the machine usage time in product manufacture. From the matrix of products of the facility, it was found that product $F$ contained three practically insoluble ingredients: betamethasone valerate, tolnaftate and cliquinol [26]. Also, product $\mathrm{F}$ cream had the largest percentage of the machine usage time due to its frequent production and a large batch size.

Three consecutive batches of the worst case product were taken into account to validate the corresponding cleaning procedures for the machines. Cleaning and sampling were performed after each product.

\section{Cleaning procedure}

The cleaning procedure involved a commercial detergent (Kamena L.A.11) with the following specifications:

Anionic active material 5 - $15 \%$, non-ionic surfactant $5 \%$, preservative $5 \%$, viscosity: 200 $600 \mathrm{cps}$ at $25^{\circ} \mathrm{C}$ and color was clear light yellow at $25^{\circ} \mathrm{C}$.

\section{Procedure for cleaning the preparation tank}

A quantity of 500 liters of hot purified water (70 $90{ }^{\circ} \mathrm{C}$ ) was added to the preparation tank with stirring by operating the inner mixer for $15 \mathrm{~min}$ to get rid of any remaining product residue and then the water was discarded. The tank was washed with 100 liters of purified water mixed with the detergent $(60 \mathrm{ml}$ detergent to each 1 liter of purified water), then the inner and outer tank mixers were operated as well as operating the

Trop J Pharm Res, November 2016; 15(11): 2331 
homogenizer for $30 \mathrm{~min}$. Then, the solution was discarded and the preparation tank was filled with 250 liters of hot purified water $\left(70-90^{\circ} \mathrm{C}\right)$, the inner and outer mixers and the homogenizer were operated for $15 \mathrm{~min}$ for rinsing the tank followed by solution discarding. The above was repeated using 250 liters of purified water for rinsing the tank. The tank was then dried with compressed air and sprayed with isopropyl alcohol $70 \%$.

\section{Procedure for cleaning transfer bin}

The inner surface of the transfer bin, the cover and the stainless steel tube were washed first with hot purified water $\left(70-90{ }^{\circ} \mathrm{C}\right)$ to get rid of any remaining product residues. Then, they were washed with the detergent and hot purified water $\left(70-90{ }^{\circ} \mathrm{C}\right)$, rinsed with hot purified water $(70-$ $90{ }^{\circ} \mathrm{C}$ ) and finally with purified water two times before they were dried with compressed air and sprayed with isopropyl alcohol $70 \%$.

\section{Procedure for cleaning of cream and ointment filling machine}

Tubes were removed from the machine. Any product residue appearing on the machine surface was removed. The machine parts were dismantled (hopper, transfer hoses, filling nozzle and the machine set) and transferred to the washing room. The machine body was wiped with clean cloth soaked in hot purified water (50 $-60{ }^{\circ} \mathrm{C}$ ) followed by another one with purified water and dried with compressed air then sprayed with isopropyl alcohol $70 \%$.

In the washing room, the machine parts were washed with hot purified water $\left(70-90{ }^{\circ} \mathrm{C}\right)$ first, then, washed with detergent and hot purified water. Then, followed the rinsing with hot purified water $\left(70-90{ }^{\circ} \mathrm{C}\right)$, and with purified water two times. The machine parts were dried with compressed air and sprayed with isopropyl alcohol $70 \%$. The machine parts were then reassembled to the machine body.

\section{Validation of the cleaning procedure}

After the cleaning process ended, the following steps were applied to validate the process.

Visual inspection: to ensure absence of product or detergent residue on machine surface. Visual examination was conducted under a light intensity of 750 lux and an angle of incidence of $90^{\circ}$. The distance between the eye and the surface examined was $30 \mathrm{~cm}$, and duration of observation was 20 seconds.

\section{Swab samples}

These were taken from machine parts which were critical hard to clean areas (Appendix 2). The swab tubes were prepared by placing $5 \mathrm{ml}$ of acidified ethanol $(0.1 \mathrm{~N}$ hydrochloric acid in ethanol $96 \%$ ) in each swab tube. The area to be sampled was marked by using stencil $25 \mathrm{~cm}^{2}$ (5 $\mathrm{cm} \times 5 \mathrm{~cm}$ ). The swab head moistened with acidified ethanol was held and the area to be sampled was wiped in a zigzag shape horizontally and vertically. The swab tube was labeled corresponding to the sample location. The tube carrying the swab head was placed in a sonicator for 30 minutes (test solution). Swab samples were analyzed for maximum allowable carryover (MACO) of betamethasone valerate, tolnaftate and cliquinol [27].

Stock standard solutions were prepared using $0.1 \mathrm{~N}$ hydrochloric acid in $96 \%$ ethanol, to obtain a solution of $12 \mathrm{mg} \%$ of betamethasone valerate (solution A), a solution of $100 \mathrm{mg} \%$ cliquinol (solution B) and a solution of $100 \mathrm{mg} \%$ of tolnaftate (solution $\mathrm{C}$ ). A standard solution containing the three ingredients was prepared by mixing $5 \mathrm{ml}$ of solution A with $10 \mathrm{ml}$ of each of solutions of $B$ and $C$.

The standard and the test solutions were filtered on $0.45 \mu \mathrm{m}$ membrane filter, and injected on HPLC in accordance to the general method of analysis. The analysis conditions involved a $\mathrm{C} 18$ column, $4.6 \times 250 \mathrm{~mm} \times 5 \mu \mathrm{m}$. The mobile phase was a mixture of acetonitrile and water (65:35), adjusted to a pH of 3.0 with phosphoric acid. The flow rate was set at $1.5 \mathrm{ml} /$ minute and the injection volume was $10 \mu \mathrm{l}$.

The content of each ingredient in the samples was calculated as in Eq 3.

Drug Content $=\left(P_{t}\right) /\left(P_{s t d}\right) \times C_{s t d} \times 1000$

Where $P_{t}$ is the peak area of drug in the test solution, and $\mathrm{P}_{\text {std }}$ is the peak area of drug in the standard solution, and $\mathrm{C}_{\text {std }}$ is the concentration of the standard.

\section{Microbiological sample}

Microbiological monitoring of the machine surface was done after machine drying. Microbiological samples were taken in a manner similar to swab sampling, yet sterile cotton swabs were used, and the sampled areas were $25 \mathrm{~cm}^{2}$ $[4,28,29]$. The swab head was taken from the swab tube and used to wipe the surface of a prepared agar plate. The agar plates were then incubated at $\left(32-38^{\circ} \mathrm{C}\right)$ for five days. At the end 
of the incubation period, the growth of microorganisms was observed and the results were recorded. Criteria of clean room standard for surface swab test were used: there should be no more than $25 \mathrm{CFU} / \mathrm{swab} 25 \mathrm{~cm}^{2}$ [1].

Rinse sample: Rinse sample of $500 \mathrm{ml}$ was collected before spraying alcohol on the machine parts to prevent interference. Final rinse samples were tested for their TOC (total organic carbon), $\mathrm{pH}$ and conductivity limits, using a TOC analyzer, $\mathrm{pH}$ meter and conductivity meter, respectively. TOC, $\mathrm{pH}$ and conductivity should conform to the specifications for water for injection. Thus TOC should not exceed 500 ppm. $\mathrm{pH}$ limit should be from $5-7$. Conductivity should not be more than $1.3 \mu \mathrm{s} / \mathrm{cm}$ [27].

\section{RESULTS}

The calculated maximum allowable carryover level of the drug in the sample was found to be 674.37 ppm. Results obtained after chemical testing of betamethasone valerate, cliquinol and tolnaftate residue by swab sampling of hard to clean (critical area) of the surface of cream and ointment preparation tank, transfer bin and filling machine - after three cleaning cycles, were below the acceptance criteria.

Visual inspection of machine surfaces showed no residue. The results of microbiological testing showed that the different machine parts conformed to the acceptance criteria $1<25$ CFU/25 $\mathrm{cm}^{2}$ ).

\section{Final rinse}

TOC analysis for cream and ointment preparation tank was not conforming to specification as it was found to be above 500 ppb. A blank sample was taken from the purified water source that was used for washing the cream and ointment preparation tank to measure its TOC content. The results were found within the limit. Thus the cause of the high TOC results was probably due to the presence of detergent residue. Consequently, the rinsing time of the tank was increased to be $30 \mathrm{~min}$ using hot purified water $\left(70-90{ }^{\circ} \mathrm{C}\right)$ instead of $15 \mathrm{~min}$. Sample repetition and analysis of the final rinse showed that the results were conforming to specifications. Thus, the cleaning procedure was changed to a rinsing time of $30 \mathrm{~min}$ and applying this during routine work.

The results of second and third washes all conformed to acceptance criteria. No residue was visible on the machine surfaces. Chemical analysis of the swab samples showed that the level of the active pharmaceutical ingredient was below the acceptance limits. Also the microbiological testing showed that all the surfaces conformed to the acceptance levels. The conductivity, $\mathrm{pH}$ measurements as well as the TOC measurements all conformed to the acceptance criteria after extending the rinsing time to $30 \mathrm{~min}$ instead of $15 \mathrm{~min}$.

\section{DISCUSSION}

The MACO was calculated using the FTU [24]. The FTU was assumed to be $20.25 \mathrm{~g}$ which was enough to cover the whole body, multiplied by four as the cream was applied four times daily [25]. The product of such multiplication produced the LDD (largest daily dose) of the next product. By knowing the MACO (674.37 ppm), it was possible to determine the maximum limit of product in the analyzed sample. Swab samples removed from critical hard to clean areas were taken as measure to the extent of success of the cleaning method to achieve its goal $[1,17,18]$.

Indirect sampling of cleaned surfaces was achieved through the rinse samples. Such samples showed to be of great value so as to detect detergent residue [18], especially in areas which were almost impossible to be accessible to swabs. Indirect sampling proved that fifteen minutes of rinsing were not enough to remove detergent residue. Thus, an extension of the rinsing time to thirty minutes was done which ensured effective detergent residue removal.

It is clear that the choice of a sensitive method of analysis is important to detect any residual product, and hence the level of cleanliness achieved [13]. Hence, the use of the HPLC method of analysis of the three components of the product was chosen.

\section{CONCLUSION}

It is possible to clean a cream and ointment production and filling facility by a simple method using purified water and a commercial detergent. The method proved to be reproducible where results obtained after three cleaning cycles showed that chemical and microbiological residues were below the maximum allowable limits. The method is also efficient. 


\section{DECLARATIONS}

\section{Acknowledgement}

The authors would like to express their deep gratitude to members of Pharco B International Pharmaceutical Company and Sigma Pharmaceutical Company for their help and for providing facilities required for the study.

\section{Conflict of Interest}

No conflict of interest associated with this work.

\section{Contribution of Authors}

The authors declare that this work was done by the authors named in this article and all liabilities pertaining to claims relating to the content of this article will be borne by them.

\section{Open Access}

This is an Open Access article distributed under the terms of the Creative Commons Attribution License, which permits unrestricted use, distribution, and reproduction in any medium, provided the original work is properly credited.

\section{REFERENCES}

1. World Health Organization. Quality assurance of pharmaceuticals. A compendium of guidelines and related materials. Volume 2, Good manufacturing practices and inspection, 2nd edn. Geneva, Switzerland; 2006; $p 418$.

2. Jatto E, Okhamafe AO. An overview of pharmaceutical validation and process controls in drug development. Trop J Pharm Res 2002; 2: 115-122.

3. LeBlanc DA. Validated Cleaning Technologies for Pharmaceutical Manufacturing. New York: Interpharm CRC Press; 2000. $305 p$.

4. Kumar VS, Sanjeev T, Sharma PK. Overview of cleaning validation in pharmaceutical manufacturing unit. Int $J$ Adv Res Pharm Bio Sci 2012; 1: 154-164.

5. Asgharian R, Hamedani FM, Heydari A. Step by Step How to Do Cleaning Validation. Int J Pharm Life Sci 2014; 5(3): 3345-3365.

6. Gawai A, Lokhande S, SamadhanMagar, Biyani KR. A review on cleaning validation in pharmaceutical industry. Int J Pharm Eng 2013; 2: 133-144.

7. Bharadia, Praful D, Bhatt JA. Review of current implementation strategies for validation of cleaning process in the pharamaceutical industry. $J$ Validation Tech 2006; 12: 218-231.

8. Patel PK, Patel NM, Patel PM. An Overview on Cleaning Validation. Int J Pharm Biol Arch 2011; 5: 1332-1336.
9. Bismuth G, Neumann S. Cleaning Validation: A Practical Approach. New York: Interpharm CRC Press; 2000; $p$ 200.

10. Fugat T. Hold Time Studies: A Lost Parameter for Cleaning Validation. J Validation Tech 2007; 13: 206209.

11. Pluta PL, Rizwan S. Cleaning Validation Challenges. J Validation Tech 2010; 16: 30- 36.

12. Chitra K, Murthy DN. A Review Article on cleaning validation. Int J Pharm Sci Res 2013; 4: 3317- 3327.

13. Pharmaceutical Inspection Convention. Validation master plan installation and operational qualification, non-sterile process validation and cleaning validation (PI 006-3). EU: PIC/S; 2006; $p 26$.

14. European Commission. Final Version of Annex 15 to the EU Guide to Good Manufacturing Practice (Qualification and validation). Brussels; 2001; $p 16$.

15. Dhole A, Pankaj B, Gulshan R. An Overview on Cleaning Validation of API Manufacturing Plant. Int $J$ Pharm Res Dev 2013; 5: 1-8.

16. Haider SI, Asif ES. Cleaning Validation Manual: A Comprehensive Guide for the Pharmaceutical and Biotechnology Industries. New York: CRC press; 2010; p 608.

17. World Health Organization. Supplementary guidelines on good manufacturing practices: validation. WHO Technical Report Series 937; 2006; $p 72$.

18. Ravindra U, Chavan V, Saraf $N$, Sable P. Cleaning validation: important aspect in pharmaceutical industry. Int J Pharm Res Develop 2012; 4(2): 1175-1179.

19. Health Products and Food Branch Inspectorate Guidance Document. Cleaning Validation Guidelines. Canada: Health Canada; 2000; $p 11$.

20. Satinder K, Shashikant $R$, Bharat P. A Review On Concept of Cleaning Validation in Pharmaceutical Industry. Int Res J Pharm 2012; 3: 17-19.

21. Lakshmana Prabu S, Suriyaprakash TNK. Cleaning Validation and its importance in Pharmaceutical Industry. Pharma Times 2012; 42: 21-25.

22. Ovais M, Lian LY. Setting Cleaning Validation Acceptance Limits for Topical Formulations. PharmTech 2008: 1 - 6.

23. Long CC, Finlay AY. The Finger Tip Unit- A New Practical Measure. Clin Exp Dermatol 1991; 16(6): 444447.

24. Lian LY, Ovais M. Setting Cleaning Validation Acceptance Limits for Topical Formulations [homepage on the internet], 2008. [cited 2016 September 11]. Available from http://www.pharmtech.com/settingcleaning-validation-acceptance-limits-topicalformulations.

25. Parenteral Drug Association: Points to Consider for Cleaning Validation, in PDA Technical Report Series No. 291998, 2012. [cited 2015 May 13]. Available from https://store.pda.org/tableofcontents/tr2912_toc.pdf.

26. The British Pharmacopeia. UK: The Stationary Office; 2009; pp 558, 2563.

Trop J Pharm Res, November 2016; 15(11): 2334 
27. United State Pharmacopeia National Formulary USP 30 NF 25. US Pharmacopoeial Convention; 2007; $p 469$.

28. Sutton $S$. The environmental monitoring program in a GMP environment. J GXP Compl 2010; 14(3): 22-30.
29. Yang $P$, Burson K, Feder D, Macdonald F. Method of Development of Swab Sampling for Cleaning Validation of a Residual Active Pharmaceutical Ingredient. Pharma Tech J 2005; 29(1): 84-94 